\title{
Processo de trabalho e produção do cuidado na Atenção Primária à Saúde durante a pandemia de COVID-19 em Florianópolis-SC: experiências vivenciadas por uma farmacêutica residente
}

\section{Working process and care promotion in Primary Health Care during the COVID-19 pandemic in Florianópolis-SC: experiences lived by a resident pharmacist}

DOI: $10.46919 / \operatorname{archv2n3-017}$

Recebimento dos originais: 01/05/2021

Aceitação para publicação: 30/06/2021

\author{
Marina Dutra Soncini \\ Farmacêutica, Especialista em Saúde da Família / Residência Multiprofissional \\ Universidade Federal de Santa Catarina \\ E-mail: marina.soncini@gmail.com
}

Leandro Ribeiro Molina

Farmacêutico, Mestre e Doutorando em Saúde Coletiva (PPGSC/UFSC)

Universidade Federal de Santa Catarina / Secretaria Municipal de Saúde de Florianópolis

E-mail: le_rmolina@hotmail.com

\author{
Luciano Soares \\ Farmacêutico, Doutor em Farmácia - UFSC \\ Professor do Departamento de Ciências Farmacêuticas / Centro de Ciências da Saúde \\ Universidade Federal de Santa Catarina \\ E-mail: luciano.soares@ufsc.br
}

\section{RESUMO}

Esse artigo é resultante do Trabalho de Conclusão de Curso da autora principal, no âmbito do Programa de Residência Multiprofissional em Saúde da Família da Universidade Federal de Santa Catarina, em parceria com a Secretaria Municipal de Saúde de Florianópolis-SC, Brasil. Tem como objetivo relatar uma experiência de trabalho na Atenção Primária à Saúde (APS), discutindo a construção do processo de trabalho e sua relação com o trabalho em si no contexto da pandemia da Covid-19, sob a perspectiva de uma farmacêutica residente. Esse é um trabalho de caráter qualitativo, que consiste num relato de experiência de abordagem narrativa e reflexiva. Os resultados estão organizados em três tópicos: mudanças no processo de trabalho; medos, desafios e dificuldades; potencialidades, superações e aprendizados.

Palavras-chave: Atenção Primária à Saúde, Assistência Farmacêutica, Covid-19, Equipe Interdisciplinar de Saúde, Formação Profissional em Saúde, Narrativa

\footnotetext{
ABSTRACT

This article is the result of the Course Conclusion Work of the main author, within the scope of the Multiprofessional Residency Program in Family Health Care at the Federal University of Santa Catarina, in partnership with the Municipal Health Department of Florianópolis-SC, Brazil. It aims to report a work experience in Primary Health Care (PHC), discussing the construction of the work process and its relationship with the work itself in the context of the Covid-19 pandemic, from the perspective of a resident pharmacist. This is a qualitative work, which consists of a narrative and reflective experience report. The results are organized into three topics: changes in the working process; fears, challenges, and difficulties; potential, overcoming and learnings.
} 
Keywords: Primary Health Care, Pharmaceutical Services, Covid-19, Patient Care Team, Health Human Resource Training, Narration

\section{INTRODUÇÃO}

A pandemia de Covid-19 atingiu o mundo em 2020 e rapidamente se transformou em uma grande crise sanitária. No Brasil, a Covid-19 também trouxe inúmeros desafios à coordenação de políticas públicas e à gestão do Sistema Único de Saúde (SUS) (LIMA; PEREIRA; MACHADO, 2020). O sucesso do manejo da Covid-19 depende muito de como o país organiza seus profissionais de saúde dentro da rede de cuidados, e o Brasil nunca havia preparado sua força de trabalho em saúde para situações de emergência em grande escala como uma pandemia (LEITE et al., 2021). Somando-se a isso, o Brasil ainda tem características de grandes aglomerados urbanos e de desigualdades sociais muito peculiares. Dentro desse arranjo se fez necessário organizar os serviços, de acordo com o nível assistencial, conforme as prioridades e as necessidades da população em cada momento vivido na pandemia.

Daumas e colaboradores (2020) salientam que para passar por uma pandemia são necessários serviços de saúde efetivos e projetados para a comunidade. A Atenção Primária à Saúde (APS) tem importante papel nesse cenário, por ser a principal porta de entrada do sistema, coordenadora dos cuidados na rede, e por trabalhar com base no vínculo com a sua comunidade adscrita (BRASIL, 2017), tendo sido fundamental no combate e controle da pandemia de Covid-19 (MEDINA et al., 2020). A APS pode manejar pacientes com sintomas leves, encaminhar pacientes mais graves, além de monitorar as consequências sociais que a pandemia pode trazer às famílias de seus territórios (DAUMAS et al., 2020).

Assim como o sistema de saúde teve de se organizar para lidar com os casos de Covid-19, os serviços, individualmente, no plano da micropolítica, também tiveram que rever e reorganizar seus fluxos de trabalho. O trabalho em saúde, considerado por Merhy (2014) como um trabalho vivo, traz uma bagagem subjetiva que é própria dos seres humanos, e a essas subjetividades se somam as tecnologias duras, dentro da micropolítica do trabalho, para compor o trabalho em saúde. Considerando as lacunas nacionais na organização dos serviços, é esperado que mudanças aconteçam no processo de trabalho da APS para cumprir sua função neste contexto, com consequente impacto nas vidas tanto de profissionais, quanto de usuários.

Algumas das mudanças apresentadas no período da pandemia têm caráter mais concreto e palpável, podendo ser facilmente percebidas e sentidas pelos usuários e profissionais dos serviços, enquanto outras têm caráter mais subjetivo e amplo, englobando percepções e sentimentos dos atores envolvidos nesses processos, que também influenciam - mesmo que de forma micro - o enfrentamento da pandemia pelos profissionais de saúde. A vida do trabalho é organizada em ambientes coletivos, onde a interação com as 
pessoas é parte constante desse processo (ARAUJO; GALIMBERTTI, 2013), e, portanto, também é fator influenciador do trabalho em saúde.

Considerando que o processo de trabalho em saúde se dá de forma complexa, sendo sua construção influenciada direta e indiretamente por diferentes fatores e atores e que a forma com que este é constituído interfere diretamente na produção do cuidado em saúde, esse trabalho tem como objetivo relatar uma experiência de trabalho na APS, discutindo a construção do processo de trabalho e sua relação com o trabalho em si no contexto da pandemia da Covid-19, sob a perspectiva de uma farmacêutica residente.

\section{METODOLOGIA}

Esse é um trabalho de caráter qualitativo, que consiste num relato de experiência de abordagem narrativa e reflexiva. A pesquisa narrativa pode ser descrita como a coleta de histórias sobre determinado tema, cujas informações são utilizadas para a compreensão de determinado fenômeno ou momento (PAIVA, 2008). No presente estudo, o objeto de análise foi uma autonarrativa em que os dados estavam em forma de um texto de campo (MARIANI et al., 2012), elaborado entre os meses de março a setembro de 2020. Esse artigo é resultante do Trabalho de Conclusão de Curso da autora principal, no âmbito do Programa de Residência Multiprofissional em Saúde da Família da Universidade Federal de Santa Catarina (UFSC), em parceria com a Secretaria Municipal de Saúde de Florianópolis-SC.

A narrativa se dá na esfera pública, onde acontecem o falar e o agir, e onde também se encontra seu papel político (CAMASMIE, 2007). Sendo assim, uma autonarrativa permite não apenas a compreensão distanciada do locutor de si mesmo, como também sua compreensão sobre o meio a sua volta (MUÑOZ, 2014). Considerando que essa narrativa se insere no contexto da pandemia da COVID-19, a compreensão se estende para um momento singular da atualidade, que envolve percepções pessoais e questões sociais.

O texto de campo foi utilizado para construção de um relato de experiência que discute o processo de trabalho de uma Unidade Básica de Saúde (UBS) inserida na APS da cidade de Florianópolis-SC. Tratase de uma das maiores UBS do município, a qual abriga o trabalho de sete Equipes de Saúde da Família, neste trabalho identificada pelo pseudônimo "UBS da Ilha". A análise do texto foi feita segundo Marques e Satriano (2017), categorizando o texto de campo pela intensidade, repetição e relevância dos temas que apareciam, e seguindo com a escrita de um novo texto a partir das impressões e pensamentos que permeavam com a leitura e análise do texto de campo.

\section{RESULTADOS E DISCUSSÃO}

\subsection{MUDANÇAS NO PROCESSO DE TRABALHO}

No dia 12 de março de 2020 os dois primeiros casos de Covid-19 em Florianópolis foram confirmados. Nesse mesmo momento, a equipe de profissionais da UBS da Ilha se encontrava reunida para 
uma reunião geral da UBS, que visava justamente começar a discutir a preparação da rede de atenção à saúde para a chegada do novo coronavírus.

As mudanças que se iniciaram na semana seguinte envolveram desde a reorganização dos espaços internos até as providências para adequar vestimentas e disponibilizar Equipamentos de Proteção Individuais (EPIs) para os profissionais. Uma área da UBS foi separada e isolada para atendimento de usuários com sintomas respiratórios (possíveis casos suspeitos de Covid-19), onde trabalhavam todos os dias um médico e uma enfermeira. Para todos os tipos de atendimento, os profissionais passaram a usar máscaras cirúrgicas ou máscaras do tipo N95 (com filtro especial), a depender do local onde estavam trabalhando. Reuniões diárias começaram a ser feitas antes da abertura da UBS, onde participavam todos os profissionais, residentes e estudantes, a fim de organizar as escalas e postos de trabalho dentro da UBS.

Uma nova triagem de entrada foi adotada por todas as UBS do município, onde um profissional de saúde buscava identificar usuários que apresentassem sintomas correspondentes à Covid-19. O método de atendimento via aplicativo de mensagens também foi estimulado, com objetivo de diminuir a circulação de pessoas dentro da UBS. As reuniões das equipes de saúde da família foram suspensas e as ilhas de atendimento - local onde normalmente se faz o primeiro acolhimento do usuário por sua respectiva equipe de saúde da família - foram dissolvidas, de forma que os profissionais de medicina e enfermagem passaram a trabalhar principalmente no modelo de planilha única - sem a vinculação paciente-equipe de saúde da família.

Paralelamente a essas mudanças iniciais, o governo do estado de Santa Catarina decretou estado de emergência e o fechamento do comércio, do transporte coletivo e de todas as atividades consideradas não essenciais, inicialmente por sete dias, tendo sido prorrogado na sequência (SANTA CATARINA, 2020). Foi um período importante para o serviço se estruturar, organizar e normalizar algumas novas rotinas, agora incumbidas à APS, além de receber os EPIs necessários. Logo em seguida, foi decretado pela gestão municipal a obrigatoriedade do uso de máscaras em todo o território municipal.

Apesar da capacidade limitada para atuar nos casos graves da COVID-19, a APS, quando bem organizada, com pessoal suficiente e bem treinado, e com protocolos e insumos necessários, pode fazer a diferença ao manejar e acompanhar os casos leves, influenciando na incidência de infecção e na morbimortalidade (DAUMAS et al., 2020). A gestão municipal, desde o princípio, enviou orientações e protocolos para as suas unidades básicas, porém muitos aspectos do arranjo dos profissionais nos novos postos de trabalho teve de ser feito localmente. Além disso, a equipe da UBS sentiu a demora da gestão em liberar algumas determinações, principalmente em questões epidemiológicas, tendo então se adiantado em algumas práticas, como o monitoramento de casos suspeitos e confirmados.

Assim se estruturou uma gestão local para o trabalho durante a pandemia da Covid-19 na UBS da Ilha, que manejava da melhor forma possível os recursos disponíveis. Se já era um desafio em tempos pré- 
pandêmicos, dentro de um contexto de atendimentos reduzidos e de intensificação dos processos de teleatendimentos, a integralidade do cuidado se tornou um ponto importante para a discussão da equipe de trabalho.

O maior interesse da equipe local da UBS nessas semanas iniciais foi garantir a maior segurança possível para profissionais e usuários, enquanto se buscava atender e entender as novas demandas geradas pela Covid-19. Para atingir esse objetivo, incansáveis discussões e reuniões para organização de fluxos e escalas passaram a acontecer, dentro do contexto da reorganização do processo de trabalho já antes comentada, para possibilitar ainda maior colaboração entre a equipe. A UBS da Ilha já tem no seu histórico a construção coletiva e a gestão mais horizontalizada, caracterizada por decisões colegiadas e pelo estímulo à participação ativa dos profissionais que lá trabalham. Além disso, a UBS tem o caráter de centro de saúde escola, onde a presença de estudantes reforça a discussão crítica e contínua. Durante a pandemia, além dos residentes já alocados na unidade, a UBS da Ilha recebeu alunos do programa Brasil Conta Comigo do governo federal, que convocou estudantes de graduação dos últimos anos das áreas da saúde para trabalhar no combate à pandemia. Essas características prévias seriam importantes para as discussões que se seguiram com a chegada da Covid-19.

O trabalho se moldou de forma extremamente dinâmica, com novas orientações para a identificação e atendimento de sintomáticos respiratórios chegando todos os dias. Entretanto, vale ressaltar que nos diversos informativos enviados pela secretaria de saúde, nenhum deles continha instruções sobre o trabalho nas farmácias da rede, como o uso de EPIs adequados, por exemplo. O resultado foi novamente uma organização local da farmácia da UBS da Ilha, que considerou sua realidade para estabelecer como seria o processo de trabalho dos farmacêuticos.

O trabalho nas farmácias das unidades básicas e, mais especificamente, na farmácia de referência da UBS da Ilha, tem um fluxo particular, que se diferencia dos outros atendimentos da UBS, tanto em dinâmica, quanto em volume de atendimentos. A farmácia possui uma alta demanda de atendimentos, sendo um local com grande fluxo de pessoas - de 200 a 250 usuários por dia - sendo comum o acúmulo de usuários na sua sala de espera, enquanto aguardam atendimento. Sendo assim, as mudanças começaram pela alteração do local das senhas de atendimento para a farmácia, que foram para a entrada da UBS, onde o fluxo de pessoas seria controlado para evitar os aglomerados na sala de espera.

Além disso, a sala de atendimento de sintomáticos respiratórios foi colocada ao lado da farmácia, onde tinham dois consultórios utilizados anteriormente pelos profissionais do Núcleo Ampliado de Saúde da Família e Atenção Básica (NASF-AB). Assim, a entrada da farmácia que dava direto para a rua ficou sendo utilizada apenas para entrada de pacientes para a área de sintomáticos, e um dos guichês de atendimento da farmácia entrou para essa mesma área, separada das demais por biombos e utilizada apenas para atender os pacientes sintomáticos que precisavam de medicamentos. Essa conformação, permitiu à 
farmácia da UBS da Ilha se diferenciar da maioria das farmácias da rede municipal, por ter o profissional farmacêutico fazendo a dispensação diretamente na área de sintomáticos, sem que os pacientes ou os profissionais que atendiam na área precisassem se deslocar pela UBS, evitando assim, exposição de outros profissionais ou usuários.

A prefeitura criou um site que mostrava a situação epidemiológica do município, assim como a sala de situação do Covid-19, chamado Covidômetro (FLORIANÓPOLIS, 2020b). Após alguns meses com o número de casos de Covid-19 controlados e os fluxos mais bem estabelecidos, veio a retomada do funcionamento do comércio, da oferta de transporte por ônibus e, consequentemente, da demanda que havia ficado reprimida por, pelo menos, quatro meses. Nesse momento, a quarentena e o isolamento social já não estavam mais sendo praticados de forma tão rígida pela população, sendo comum pessoas circularem sem usar máscaras de proteção. Junto com isso, ao final de junho, observou-se um aumento no número de casos de forma exponencial no município, que o colocou em situação epidemiológica gravíssima, segundo a Secretaria Estadual de Saúde de SC, situação na qual, com exceção de poucos momentos, o município de Florianópolis se encontra desde então até submissão deste relato.

\subsection{MEDOS, DESAFIOS E DIFICULDADES}

Apesar do serviço da UBS da Ilha ter se organizado internamente, ter trabalhado em conjunto e interprofissionalmente, com discussões e críticas sempre muito aguçadas, é comum que dificuldades ocorram ao longo do processo. A pandemia, por si só, já se caracteriza como um enorme desafio, e tentamos aqui destrinchar, um pouco mais, pequenos e grandes desafios que permearam e compuseram a realidade do trabalho em saúde durante este período. Essas dificuldades enfrentadas pelos profissionais vinham tanto de dentro quanto de fora do ambiente de trabalho. Nas primeiras semanas, os sentimentos que se mostraram mais presentes foram a insegurança, a ansiedade vinda do novo, e certo anseio para fazer acontecer, característica clássica dos profissionais da UBS da Ilha.

Se considerarmos a teoria do trabalho vivo em ato de Merhy (2014), em que o trabalho em saúde se dá no exato momento em que é executado, e que parte desse trabalho é permeado pela produção de subjetividades do próprio trabalhador também em ato, tudo que é vivido e experienciado pelo profissional, seja dentro ou fora do ambiente profissional, irá influenciar sua produção de sentidos e significados no momento de produção do trabalho.

A pandemia da Covid-19 trouxe muitas situações novas para os profissionais de saúde, que passaram a ter de lidar com as mudanças de protocolos de atendimentos quase diários, com uma nova carga de roupas e equipamentos de proteção, com a privação do toque e da proximidade durante os atendimentos e com o medo de se contaminar. Essas e outras mudanças tiveram que ser absorvidas rapidamente pelos profissionais para serem colocadas em prática. Os trabalhadores tiveram que aprender a lidar com 
sentimentos e frustrações gerados no processo, no decorrer da pandemia, de forma concomitante ao exercício profissional, exigindo, assim, muita estrutura física e psicológica. Ornell e colaboradores (2020) relembram que enquanto os momentos de lockdown e de incentivos ao isolamento social estavam acontecendo ao redor do mundo para reduzir as chances de novas infecções, os profissionais de saúde iam em outro sentido. No trabalho, iam todos os dias ao encontro de casos suspeitos ou confirmados de Covid19 e, quando em casa, vivenciavam o medo da possibilidade de transmitir a infecção para seus familiares.

Assim como o próprio curso da pandemia foi se modificando em termos de índice de contágio, a reação dos profissionais foi também mudando conforme o que se apresentava no cotidiano do trabalho e da vida fora dele. Se no início predominava o medo, a incerteza e as mudanças, a partir do quinto e sexto mês - mais ou menos julho e agosto - o que se destacou no cenário da UBS da Ilha foi o excesso de trabalho e o cansaço físico e mental. Estudos mostram que a alta demanda, a falta de recursos humanos, falta de apoio e incentivo e uma difícil relação entre a equipe de profissionais são fatores geradores de estresse relacionados ao trabalho em saúde (ALMEIDA et al., 2016; LENTINE; SONODA; BIAZIN, 2020; MOLINA; HOFFMANN; FINKLER, 2020). Os fatores geradores de estresse são vivenciados de formas diferentes por cada pessoa (SANTOS et al., 2011), e assim também vão influenciar de formas diferentes a relação do trabalhador com o seu trabalho, moduladas pelas subjetividades individuais. Além disso, na questão de geradores de estresse, a forma com que o trabalho é organizado também influencia nesse quesito (OLIVEIRA; CUNHA, 2014). Além disso, elementos da organização do processo de trabalho como relações de poder, ritmo de trabalho, divisão das tarefas e etc. são também entendidos como fontes laborais de tensão (OLIVEIRA; CUNHA, 2014). Na UBS da Ilha, foi possível notar o estresse que tomava conta das equipes através da sensação de nunca dar conta da demanda, de dias intensos, da perda de controle dos monitoramentos dos casos de Covid-19 do território, entre outras coisas.

Com o passar dos meses, ficou evidente que os esforços pela eficiência e agilidade no atendimento de casos suspeitos, assim como as estratégias de comunicação para a educação em saúde da população da UBS da Ilha não estavam sendo suficientes para diminuir a velocidade do contágio no território. Nesse momento, os sentimentos do início foram sendo somados ou mesmo substituídos, aos poucos, por sensações de impotência para mudar os rumos da realidade durante a pandemia no território e no município. As subjetividades vão sendo construídas através dos acontecimentos que chegam até aos sujeitos, no caso os profissionais de saúde, impactando assim sua forma de ver o mundo (FRANCO; MERHY, 2013) e, consequentemente, seu trabalho. Nota-se então que as subjetividades, como é esperado, vão se modificando à medida que as fases vividas dentro da pandemia também vão evoluindo.

É inegável dizer que em alguns momentos a frustração e mesmo a raiva se sobressaiam, principalmente vindas daquela sensação de estar sempre 'enxugando gelo'. Na APS é quase impossível 
cuidar sem contar com a participação e compreensão dos usuários, que têm maior autonomia e participação no controle dos seus cuidados (LIMA et al., 2009).

Vejo como importante também a compreensão da realidade de cada pessoa e/ou família, principalmente durante a pandemia, quando muitos entraram em situação de vulnerabilidade. Um desafio para a APS é encontrar instrumentos, mediações e condições organizacionais que, dentro do possível para a realidade vivida, possam atingir certo nível de cuidado em saúde, seja ele individual ou coletivo (ZOBOLI, 2009). Assim, os esforços eram voltados para o isolamento de casos suspeitos e confirmados, a identificação de seus familiares e a tentativa de diminuir a circulação do bairro como medida preventiva de contágio por meio da educação em saúde. A medida que as tentativas de orientações não funcionavam, mesmo utilizando-se dados científicos para atingir a emoção e os simbolismos para persuasão daqueles que poderiam seguir as regras de distanciamento, o cansaço da equipe aumentava, juntamente com o número de casos no território e no município.

Vários pontos que cercam essa subjetividade dos profissionais podem ser considerados. Inicialmente, constitui uma abordagem da Saúde Pública ações que restringem certas liberdades individuais, justificadas pela premissa de que o bem comum tem prioridade sobre o interesse individual (GAUDENZI; SCHRAMM, 2010). O fundamental é que a autonomia do sujeito, que é muito apreciada pelos serviços de saúde da APS, venha acompanhada de responsabilidade, reforçando a corresponsabilização entre serviço e usuários, de forma análoga a responsabilidade de cada um para com a comunidade como um todo. Em outras palavras, entende-se que há responsabilidade de quem pode e tem condições sociais para tal, em restringir certas liberdades para proteção própria, e para proteger aqueles que não têm condição de manter o adequado isolamento social, seja por motivos profissionais ou financeiros.

Além disso, fatores ligados às condutas adotadas tanto pela gestão municipal quanto pelo governo estadual e federal parecem ter dificultado muito o controle da pandemia, e assim sobrecarregado ainda mais os profissionais de saúde. Quando, em pleno aumento do número de casos, se toma a decisão de manter o comércio e outras atividades liberadas, a mensagem que é passada para a população, que tem um conhecimento mais superficial sobre a situação sanitária, é de que tudo está sob controle. Em muitos momentos foi notável a frustração na UBS pelo discurso da necessidade do distanciamento não ser promovido nas mídias e propagandas veiculadas. Somando-se a isso, o que víamos no dia a dia dos atendimentos não condizia com às informações epidemiológicas divulgadas pelo município, o que gerava mais frustração. O Conselho Municipal de Saúde de Florianópolis elaborou diversos relatórios situacionais de análise de risco do município (FLORIANÓPOLIS, 2020a) que, em muitos momentos, divergiam da análise de risco divulgada pela secretaria municipal de saúde através do Covidômetro (FLORIANÓPOLIS, 2020b). 
Em determinado momento, a prefeitura optou por seguir as diretrizes de risco da secretaria estadual de saúde, seja por manter um padrão estadual de risco ou apenas para se eximir da responsabilidade sobre certas decisões que impactam a economia. De qualquer modo, quando o nível de risco mudava, pouco mudava a rotina da cidade, que não via fiscalização e nem restrições suficientes. Enquanto isso, o número de casos começava a aumentar de forma acelerada, assim como a ocupação dos leitos de UTI. Em um episódio de claro descaso com a situação, quando, em meados de julho, o site do covidômetro passou a informar risco gravíssimo na cidade de Florianópolis (FLORIANÓPOLIS, 2020b), as informações sobre as restrições pertinentes a esse nível chegaram a sumir do site oficial da prefeitura, evidenciando a perspectiva assumida pela gestão municipal em suas determinações. O reflexo dessas ações no dia a dia do processo de trabalho da UBS da Ilha - assim como, potencialmente, em outras UBS - era direto e evidente, culminando no aumento do nível de cansaço e do estresse dos seus profissionais.

O contexto político nacional também influenciou muito a forma com que a população e as secretarias municipais e estaduais lidaram com a pandemia. Desde o início da pandemia, com discursos e opiniões vagas sobre as estratégias de enfrentamento à Covid-19, o governo federal, pela figura do presidente Jair Bolsonaro, foi impingindo sua ideologia à frente da preservação da vida dos brasileiros e estimulando seus seguidores a trilharem o mesmo caminho.

Os primeiros meses foram marcados pelas dificuldades e desencontros entre o presidente e o Ministério da Saúde, que culminaram em duas trocas consecutivas do titular da pasta, com consequentes transições das equipes técnicas. Conjuntamente, diferenças entre governos federal, estaduais e municipais também aconteciam, e enfrentamentos do presidente com parcelas da sociedade - como a comunidade científica - dificultavam ainda mais uma coordenação coesa dos esforços de enfrentamento à Covid-19 (LIMA; PEREIRA; MACHADO, 2020). A pandemia encontrou um Brasil governado pela ultradireita, militarizado (COSTA; RIZZOTTO; LOBATO, 2020), vulnerabilizado e com grandes cortes no tecido das políticas sociais (WERNECK; CARVALHO, 2020). Junto, nesse quadro de vulnerabilidade, encontram-se também o próprio SUS e as políticas de incentivo à ciência nacional, que sofreram grandes cortes desde a EC 95 até as políticas econômicas do atual governo (WERNECK; CARVALHO, 2020).

Além de não comandar as ações, o governo federal, principalmente através do presidente, ainda se posicionou enfaticamente contrário às medidas protetivas como o isolamento social e o uso de máscaras, além de incentivar o uso de medicamentos para tratamento precoce da Covid-19 que não possuíam evidências científicas de eficácia. O presidente tratou a pandemia de forma reducionista, ridicularizou quem praticava o isolamento social, diminuiu a gravidade de mais de mil mortos por dia, desrespeitou famílias que perderam seus entes e envergonhou o Brasil mundo afora. Do imenso gasto com a compra dos medicamentos para o tratamento precoce à falta de prioridade para a aquisição das vacinas, passando pela falta de auxílio às famílias e aos pequenos negócios, o período foi marcado pelo escancarar da política que 
Bolsonaro já se propunha a fazer em 2018 na sua campanha: negacionista, violenta e genocida. Incentivando seu eleitorado fiel a seguir seus pensamentos e comportamentos, Jair Bolsonaro movimentou a polarização política para assuntos técnicos e científicos, influenciando diretamente o comportamento da população, a carga de trabalho dos profissionais de saúde e os rumos da pandemia no país.

Costa, Rizzotto e Lobato (2020) apontam que os acontecimentos relacionados ao governo federal, ao longo da pandemia, não se deveram apenas à incompetência, mas sim a uma política econômica às custas da vida dos brasileiros. Naturalmente, com o enorme quadro de desigualdade no Brasil, as consequências da Covid-19 e a distribuição do infortúnio se deram e se dão de forma desigual. Ato contínuo, a recuperação econômica, a superação dos traumas e a reconquista de padrões sociais vão acontecer também de forma desigual. As parcelas da população que terão maiores dificuldades serão aquelas já marginalizadas e negligenciadas, como a população periférica, negra e pobre, população as quais estão mais sujeitas às políticas violentas do governo Bolsonaro (LIMA; BUSS; PAES-SOUSA, 2020).

O aumento da ocupação dos leitos de UTI em Santa Catarina demorou para subir em comparação com outros estados do país. E em Florianópolis, quando ocorreu, encontrou uma APS já saturada pela demanda acumulada de outros meses e pelos novos casos de Covid-19 que apareciam. Muitos artigos apontam a importância e necessidade da atuação da APS, não apenas no manejo e acompanhamentos de casos leves de Covid-19, mas na continuidade do cuidado de pacientes crônicos e manejo das possíveis consequências do isolamento durante a pandemia (DAUMAS et al., 2020; KIDD, 2020; SARTI et al., 2020).

Savassi e colaboradores (2020) esboçam que o cenário de demandas da pandemia para a APS se dará em três grandes ondas: casos de Covid-19, queixas agudas e crônicas secundárias a não procura pelo serviço, e casos de saúde mental decorrentes das duas ondas anteriores. Em Florianópolis, a onda de contágio se deu em um tempo diferente de outros locais do Brasil. O primeiro fechamento do comércio e restrição ao acesso presencial na UBS se iniciou em março, e o crescimento da curva de contágio se deu no final de junho, e desde então sofreu apenas uma pequena queda em setembro, com seguinte crescimento novamente e permanência em altas taxas de transmissibilidade do vírus (FLORIANÓPOLIS, 2020b).

Um estudo que analisou as tomadas de decisão do governo de Florianópolis indicou que, a partir de maio e junho, as medidas adotadas estavam, em sua maioria, dissonantes com a situação epidemiológica do município (GARCIA et al., 2020), configurando um indicativo do que pode ter colaborado para o grande aumento de casos após o primeiro fechamento. Essas características e fatores podem ter levado a uma sobreposição das chamadas ondas descritas anteriormente, onde as queixas agudas e crônicas reprimidas, vieram a aparecer no serviço juntamente com o momento de alta de casos no município e no território. A consequência foi a altíssima demanda para a APS, quando a percepção, tanto para população, quanto para profissionais era de cansaço e de fragilidade. 
As múltiplas formas de acesso que a APS de Florianópolis disponibiliza a seus usuários têm grandes vantagens para o acesso aos serviços e à manutenção do vínculo - foram e são de extrema importância dada a necessidade do distanciamento social. O uso do teleatendimento e telemonitoramento de casos suspeitos foi incentivado e priorizado, e colocado como grande trunfo da gestão municipal de saúde, como medida de ação contra a Covid-19 (SILVEIRA; ZONTA, 2020). Entretanto, o aumento das formas de acesso, com a implementação do WhatsApp para agendamentos e teleconsultas, além do telefone, e-mail e demandas presenciais, que já eram rotineiros, aumentou em muito as funções nas quais se necessitava de profissionais dentro do serviço. A UBS da Ilha possuía comunicação por Whatsapp em todas as equipes de saúde da família, equipe farmacêutica, de odontologia, de marcação de exames e consultas da atenção secundária, além de prestar serviços de agendamento de vacinas e cadastro de novos pacientes por meio do aplicativo de mensagens. Todos esses serviços foram implementados sem a contratação de novos profissionais para as equipes, aumentando a carga de trabalho do conjunto dos trabalhadores, já sobrecarregado.

Em meio a esse cenário, durante algumas semanas a UBS da Ilha chegou a oferecer 160 vagas para teste rápido por semana, além de ter aumentado o espaço físico para atendimento de sintomáticos respiratórios. Tudo isso sem aumento do número de profissionais e tendo que lidar com constantes afastamentos. A coordenação, junto com o corpo de trabalhadores, fazia o possível e, quase, o impossível para oferecer à comunidade os atendimentos necessários ao manejo da Covid-19 sem prejudicar outros atendimentos essenciais. De fato, a UBS da Ilha deu conta do recado da melhor forma que pode. Seus profissionais e residentes se desdobravam para ocupar e suprir todos os locais necessários, porém, muitas vezes, às custas de sua própria saúde mental e física. Os profissionais de saúde devem ter sua saúde mental priorizada, ou estarão em risco de sofrer um colapso emocional (ORNELL et al., 2020). Nesse caso, pode ser que o colapso do sistema de saúde não venha da forma como se imagina, pelos hospitais lotados e falta de leitos, mas através de profissionais que já não conseguem prestar os serviços, devido à ruína física e emocional.

No setor da farmácia, especificamente, não foi muito diferente. As residentes estavam envolvidas em diversas funções na UBS, como triagem de porta e testes rápidos de Covid-19 além do próprio trabalho na farmácia. Inicialmente, o fluxo de usuários na farmácia chegou a diminuir, talvez por receio dos pacientes em irem à UBS, porém depois dos primeiros meses, o fluxo começou a aumentar consideravelmente. Durante a pandemia várias farmácias de referência da rede municipal foram fechadas, seja por falta de profissionais ou problemas de infraestrutura, sobrecarregando aquelas que continuaram funcionando.

Araújo e colaboradores (2008) e Molina, Hoffmann e Finkler (2020) discutem que os farmacêuticos têm uma inserção limitada nas equipes de saúde, devido ao tempo limitado para tais atividades, pois a maior parte de sua carga horária é ocupada com a gestão de estoque e a dispensação em si. Na farmácia da UBS 
da Ilha, a interação com as equipes de saúde da família sempre foi facilitada e promovida, devido à presença dos farmacêuticos residentes, que se inseriram nas equipes durante os anos anteriores. Durante a pandemia, o excesso de demanda na farmácia, conjuntamente com afastamentos, novas funções e outras atividades que os residentes desempenhavam podem ter dificultado ainda mais a participação dos farmacêuticos nas reuniões e discussões de equipe. Entretanto, assim como colocado anteriormente, os farmacêuticos se desdobravam para ser possível se colocar em todos os locais e manter o melhor atendimento e serviço para a população, incluindo as discussões com as equipes de saúde. Importante salientar que sem o apoio das estagiárias de graduação, tanto do programa Brasil Conta Comigo quanto estágio obrigatório da UFSC, não teria sido possível manter todas as atividades em andamento.

A dispensação de medicamentos foi desde o início considerada um serviço essencial da UBS e que não poderia ser interrompido. Um estudo colocou que em momento de crise global ou local, pacientes em uso de medicamentos contínuos tendem a piorar sua adesão medicamentosa (CADOGAN; HUGHES, 2021). Como o acesso a consultas médicas e de enfermagem esteve limitado em alguns momentos, a dispensação se mostrou ainda mais importante para a manutenção e o acompanhamento do tratamento dos pacientes, principalmente crônicos, que fazem uso de medicamentos de uso contínuo. Entretanto, a equipe da farmácia também descobriu dificuldades durante a própria dispensação. Como muitos dos pacientes crônicos são idosos, uma boa parte dessa população estava evitando exposição, pedindo a familiares ou a vizinhos que buscassem os remédios, ou que solicitassem a busca dos medicamentos enquanto estavam aguardando na porta de entrada do CS. Sendo assim, muitas vezes, a pessoa que vinha à dispensação não sabia dizer como estava o paciente, ou mesmo comentar sobre a adesão e os resultados do tratamento. Essas percepções vão ao encontro com as de Koster, Philbert e Bouvy (2021) de que, durante a pandemia, os pacientes também tendem a ficar menos tempo na farmácia e fazer menos perguntas aos farmacêuticos, por querer sair do ambiente com risco de contaminação, o que pode prejudicar a assistência prestada. O cuidar e acolher sem a aproximação física com o usuário, sem toque e com os sentidos do corpo cobertos por EPIs se mostrou um grande desafio (FERREIRA; BARBOSA, 2020).

A UBS da Ilha tem uma tradição de portas abertas que já vem de muito tempo. A população está acostumada a ser atendida na hora que necessita e pelo profissional da sua equipe de saúde da família. $\mathrm{Na}$ UBS da Ilha, o acesso avançado é algo muito caro, tanto para a população quanto para os profissionais, que estão sempre revendo e discutindo novas formas para facilitar o acesso aos serviços da APS. Com a triagem de porta instaurada, parte da comunidade interpretou que houve a edificação de barreiras de acesso pela UBS, o que culminou em desentendimentos e discussões entre os trabalhadores e a comunidade.

Com o retorno do comércio, as pessoas voltaram a procurar o serviço presencialmente, e se iniciou um intenso processo de comunicação com a população sobre os serviços que estavam sendo ofertados e por qual via de acesso. Considerando que a perspectiva era de que o vírus continuasse em circulação por 
bastante tempo, é compreensível que os serviços de APS tenham seus atendimentos direcionados para uma modalidade de cuidado à distância, a fim de não interromper a linha de cuidado de seus pacientes (MEDINA et al., 2020), e no caso de Florianópolis, isso se deu pelo uso de aplicativos de mensagens, como já colocado.

Divulgar essa nova forma de acesso, comunicar com o território que os serviços continuavam sendo ofertados, porém em um formato diferente, requereu da equipe e, principalmente dos residentes, um certo esforço para recriar e renovar as formas de se comunicar com a população.

Falando especificamente sobre a comunicação com finalidade de educação em saúde, o grupo de residentes criou uma série de vídeos informativos, direcionados à comunidade da UBS da Ilha, com intuito de explicar novos fluxos de atendimentos e passar informações confiáveis sobre a prevenção e tratamento do novo coronavírus, visando atenuar tensões que estavam aparecendo devido a não compreensão de certas informações. Os vídeos produzidos eram veiculados pelas listas de transmissão de WhatsApp e nas redes sociais da UBS. Essa forma de transmissão por si só já limita o alcance das informações àqueles que têm acesso à internet e às redes sociais. É provável que isso tenha influenciado na própria repercussão dos vídeos que, lançados semanalmente, atingiram mais um público de profissionais de saúde do que de moradores do território da UBS, que republicaram e encaminharam a série de vídeos Brasil afora.

\subsection{POTENCIALIDADES, SUPERAÇÕES E APRENDIZADOS}

Na UBS da Ilha atuam profissionais que compõem tanto equipes de saúde da família quanto profissionais do NASF-AB. Quando se deflagrou a pandemia, o trabalho multiprofissional foi colocado em evidência sob uma nova perspectiva, trazendo à tona não só o trabalho multiprofissional como interprofissional. Apesar de o modelo de atenção vigente colocar os profissionais de saúde subsumidos à lógica dominante biomédica, por trás das decisões e organizações práticas colocadas em funcionamento na UBS da Ilha nas primeiras semanas da pandemia em Florianópolis, existia um trabalho interprofissional fluente e muito bem coordenado pela gestão local da UBS.

Para que se chegasse às melhores pactuações possíveis, foi necessário muito diálogo entre os profissionais, entrando aqui um ponto importante do processo de trabalho na UBS da Ilha: a gestão horizontalizada. Antes da pandemia a UBS da Ilha já possuía uma gestão colegiada onde participavam representantes das equipes que compunham a UBS e, nas primeiras semanas após a chegada do novo coronavírus, elas foram substituídas por reuniões diárias com todos os profissionais, como já comentado anteriormente. Essa nova conformação se deu pela velocidade com que chegavam as informações, e sua necessidade de discussão e pactuação, assim como possibilitar que todos opinassem e ficassem cientes dos processos em constante mudança.

Uma das dimensões do trabalho vivo em ato é a relação do trabalhador com o seu ato produtivo, assim como com outros trabalhadores (MERHY; FRANCO, 2008). Se juntarmos isso à ideia de Guizardi 
e Cavalcanti (2010), de que o tempo empregado na discussão coletiva deve ser considerado como diretamente produtivo, podemos entender que as relações e diálogos estão dentro do próprio ato produtivo. Essa interação comunicante, que ficou expressa na forma coletiva de conduzir as decisões na UBS da Ilha, vem no sentido de propor uma nova forma de construção da produção do trabalho em saúde.

Como consequência dessa nova forma de construir o processo de trabalho, se espera um trabalho em saúde mais integrado. Quanto mais dialógicas forem as relações, mais integradas serão as ações em saúde (PEDUZZI et al., 2020). A integralidade das ações e dos discursos dos profissionais para com a comunidade sempre foi um ponto importante e, em meio a mudanças de fluxos, se tornou um dos pontos chave. Nem sempre a comunicação com a população ocorreu de forma coesa por parte da equipe da UBS. Em muitos momentos as informações que eram passadas se desencontraram e geraram mais estresse do que resolução dos conflitos que surgiam, e o que se seguia era uma nova reunião com novos alinhamentos. Um dos grandes objetivos era possibilitar uma comunicação clara entre centro de saúde e comunidade, e falas e ações coerentes quanto aos assuntos gerais do centro de saúde foram muito importantes para evitar desgastes com uma população já em sofrimento devido ao momento que se estava vivendo. Para que todas as pactuações funcionassem e buscassem a integralidade, se fez importante também a aceitação e escuta de opiniões diversas, que provinham de práticas diversas que, naquele momento, tinham que convergir. Entra aqui o que já foi falado anteriormente, que o discutir também faz parte do trabalho em saúde.

Além disso, a construção dialógica trouxe a sensibilização e a corresponsabilização da equipe de profissionais do centro de saúde. Já em tempos 'normais' é esperado que todos os trabalhadores da UBS entendam os fluxos e funções de cada um, e com a pandemia, por situações como a exemplificada no parágrafo anterior, isso foi reafirmado para não se gerar dificuldades a mais daquelas já presentes. Passos e Carvalho (2015) colocam que a sensação de pertencimento e corresponsabilização são imprescindíveis para ampliar a eficácia das práticas e qualificar o trabalho.

O diálogo e as decisões coletivas, com discussões ampliadas e horizontais trouxeram esse entendimento, o da importância e o senso de necessidade de cada um da equipe, assim como a corresponsabilização como consequência. O espaço de trabalho é reafirmado, desse modo, como lócus de realização profissional (PASSOS; CARVALHO, 2015). Quando se entende o trabalho que está sendo feito no amplo espectro, se entende o seu papel dentro daquele processo, ficando muito mais fácil e, até mesmo, prazeroso a construção da produção do trabalho no coletivo. O trabalho de um depende do trabalho do outro, sendo todos os envolvidos responsáveis pela prestação de cuidado que chega à população.

Entretanto, se observa que a proposição do diálogo por si só talvez não fosse suficiente para fazê-lo acontecer. O perfil de profissionais da UBS, que em grande parte acreditam muito no potencial da APS e se doam para sempre melhorar o serviço, visando à defesa do SUS, ao nosso ver, foi crucial para que as pactuações dialógicas acontecessem e gerassem respostas práticas. 
Para além de ações integradas e resolutivas, o diálogo e as reuniões construídas tiveram também um outro viés. Os encontros entre os profissionais aconteciam não apenas nas reuniões já citadas, mas casualmente entre almoços e cafés que antes não se faziam conjuntamente. Essa interação ganhou uma potência de autocuidado, pois se dava como um momento de descontração e aproximação. Ceccim (2018) coloca que a interprofissionalidade também favorece a rede de laços afetivos, como descrito acima, e que isso intensifica a sensação de pertencimento a uma equipe. O pertencimento, por sua vez, projeta o sentimento de não-solidão, de que por maiores as dificuldades que a pandemia traga, não estaremos sozinhos.

O local de trabalho estava direta, ou indiretamente, relacionado a fatores desencadeantes de tristeza e estresse, mesmo que apenas na lembrança contínua da situação vivida, como as máscaras usadas durante todo o tempo não nos deixavam esquecer. Fazer com que esse local seja também um espaço protetor para os profissionais não é uma tarefa fácil (MACAYA; ARANDA, 2020), mas é uma potência para a compreensão e aceitação das questões que estavam formando àquela nova realidade. $\mathrm{O}$ medo e a insegurança que, em diferentes graus, atingiram os profissionais de saúde, assim como a tristeza, descrença, raiva e frustração, impulsionaram, talvez pela força da necessidade, a expansão das relações interprofissionais para uma rede de apoio.

Ornell e colaboradores (2020) quando fala da saúde dos profissionais de saúde durante a pandemia de Covid-19, concorda que um ambiente de trabalho que possibilite a expressão de sentimentos e sintomas relacionados ao burnout e à exaustão emocional são não só importantes, como necessários. Essa dimensão de promoção da saúde e autocuidado também foi vista no retorno da reunião semanal de residentes, inicialmente suspensa. Além de planejamentos, produção de material audiovisual e formações temáticas, as reuniões acabaram sendo um espaço seguro de desabafo e compartilhamento das frustrações relacionadas tanto às questões do trabalho e da formação como residente quanto da vida pessoal, que envolvia a saudade da família, o isolamento e a falta de afetos.

No âmbito da farmácia da UBS, a dispensação de medicamentos não foi interrompida em praticamente nenhum momento, sendo garantido o acesso da população aos medicamentos durante a pandemia. As receitas de uso contínuo tiveram sua validade estendida para um ano no município (FLORIANÓPOLIS, 2020c) e a dispensação desses era feita para dois meses de tratamento, reduzindo o movimento de usuários na farmácia assim como a exposição dos mesmos à UBS. Nos momentos em que a área isolada de sintomáticos respiratórios foi alocada no andar acima da farmácia, também foi organizado um estoque de medicamentos básicos a serem dispensados dentro da própria área de sintomáticos, funcionando como uma pequena farmácia setorial.

O serviço também adotou o uso de smartphone para comunicação com a população, principalmente via aplicativo de mensagens WhatsApp. Essa forma de acesso já era usada pelas equipes de saúde da família 
e, com a pandemia, foi incentivada como primeira forma de acesso pelas mesmas. O whatsapp ficava sempre em posse de algum farmacêutico, e as mensagens eram respondidas durante o período em que a UBS estava aberta - das $8 \mathrm{~h}$ às $17 \mathrm{~h}$.

Os profissionais farmacêuticos, por meio das residentes, se inseriram em outras funções vinculadas ao combate à pandemia na UBS que extrapolaram o espaço físico da farmácia. Tiveram participação na produção do material audiovisual informativo direcionado à comunidade, participavam das escalas de triagem de porta, executavam testes rápidos para detecção de anticorpos para a Covid-19, assim como aconselhamento pré e pós teste a depender do resultado, e ainda, através da Comissão de Farmácia e Terapêutica do município estiveram envolvidas na elaboração de um parecer acerca dos possíveis medicamentos a serem utilizados para a Covid-19.

A Política Nacional de Assistência Farmacêutica (PNAF), um marco para a profissão no Brasil, tira o foco da atuação dos farmacêuticos dos medicamentos e coloca-os sobre o usuário. A profissão farmacêutica vem construindo sua identidade no SUS, e a PNAF não define o escopo de atuação do farmacêutico na atenção básica (SATURNINO et al., 2012). Não seria surpreendente que, por ser uma atuação em construção, residentes farmacêuticas atuando em um serviço de APS que lhes possibilite certa autonomia, explorem, construam e reforcem a atuação farmacêutica dentro da pandemia. Desse modo, a residência constrói o profissional ao mesmo tempo em que o residente ajuda a construir a profissão. O que foi percebido é que a pandemia pode ter colocado, mesmo que minimamente, mais uma luz sobre as possibilidades e potencialidades da profissão farmacêutica na APS e no SUS.

\section{CONSIDERAÇÕES FINAIS}

O período de pandemia vivido em 2020 acarretou inúmeros desafios aos serviços de saúde e aos seus profissionais. A própria demanda decorrente dos casos de Covid-19, somadas às demandas já existentes na APS, causaram um aumento expressivo de trabalho para os profissionais da APS. O aumento da demanda, junto com outras situações vividas devido ao isolamento social, ao medo de infecção e a vontade de trabalhar da melhor forma possível trouxeram uma nova carga de estresse e pressão psicológica aos trabalhadores da APS. Aos residentes, que ainda viviam situações específicas quanto às influências em suas formações profissionais, o adoecimento físico e psíquico pode ter se mostrado ainda maior.

Segundo as percepções aqui colocadas, a situação política em que vive o Brasil, as decisões tomadas e as que foram deixadas de se tomar pelo governo federal e pelas gestões estadual e municipal de saúde parecem ter impactado diretamente o cotidiano de trabalho dos profissionais, assim como o curso da pandemia de Covid-19 no município de Florianópolis e no Brasil. Os serviços da UBS e os profissionais que o compuseram sentiram diretamente as consequências de irresponsabilidades coletivas de um governo irresponsável e violento. 
Entretanto, aprendizados e superações também foram tirados desse período. Algumas novidades introduzidas no processo de trabalho devem permanecer na APS após o término da pandemia, como o uso de aplicativo de mensagens. Na residência, houve um acúmulo de experiência que trouxe ainda mais crescimento e maturidade profissional. Ademais, o apoio entre o corpo de profissionais da UBS, o senso de coletividade e principalmente os afetos envolvidos nos processos de construção coletivos parecem ter aliviado a pressão sentida pelos agentes que compõem a APS e, mais especificamente, que compõem a UBS da Ilha, centro de saúde que serviu de foco para essa narrativa.

Se as cicatrizes deixadas pela pandemia terão que perdurar em nós ainda por algum tempo, que perdure também aquelas marcas sutis deixadas pelas pessoas que compartilharam desse momento tão difícil conosco, e que tornaram tudo menos dolorido. 


\section{REFERÊNCIAS}

ALMEIDA, LA; et al.. Fatores geradores da Síndrome de Burnout em profissionais da saúde Generating factors of Burnout Syndrome in health professionals. Revista de Pesquisa: Cuidado é Fundamental Online, v. 8, n. 3, p. 4623-4628, 15 jul. 2016. http://dx.doi.org/10.9789/2175-5361.2016.v8i3.4623-4628

ARAÚJO, ALA; et al.. Perfil da assistência farmacêutica na atenção primária do Sistema Único de Saúde. Ciênc. saúde coletiva, Rio de Janeiro, v. 13, supl. p. 611-617, 2008. https://doi.org/10.1590/S141381232008000700010

ARAUJO, EMD; GALIMBERTTI, PA. A colaboração interprofissional na estratégia saúde da família. Psicol. Soc., Belo Horizonte, v. 25, n. 2, p. 461-468, 2013.

BRASIL. Ministério da Saúde. Gabinete do Ministro. Portaria no 2.436, de 21 de setembro de 2017. Aprova a Política Nacional de Atenção Básica, estabelecendo a revisão de diretrizes para a organização da Atenção Básica, no âmbito do Sistema Único de Saúde (SUS). Diário Oficial da União, Brasília, DF, 22 de set. 2017. P 68.

CADOGAN, CA; HUGHES, CM. On the frontline against COVID-19: community pharmacists ": contribution during a public health crisis. Research In Social And Administrative Pharmacy, [S.L.], v. 17, n. 1, p. 2032-2035, jan. 2021. https://doi.org/10.1016/j.sapharm.2020.03.015

CAMASMIE, AT. Narrativa de histórias pessoais: um caminho de compreensão de si mesmo à luz do pensamento e hannah arendt. 2007. 107 f. Tese (Doutorado) - Curso de Filosofia, Pontifícia Universidade Católica de São Paulo, São Paulo, 2007.

CECCIM, RB. Conexões e fronteiras da interprofissionalidade: forma e formação. Interface (Botucatu) v. 22, supl. 2, p. 1739-1749, 2018. http://dx.doi.org/10.1590/1807-57622018.0477

COSTA, AM; RIZZOTTO, MLF; LOBATO, LVC. Na pandemia da Covid-19, o Brasil enxerga o SUS. Saúde debate, v. 44, n. 125, p. 289-296, 2020. https://doi.org/10.1590/0103-1104202012500

DAUMAS, RP; et al.. O papel da atenção primária na rede de atenção à saúde no Brasil: limites e possibilidades no enfrentamento da COVID-19. Cad. Saúde Pública, v. 36, n. 6, e00104120, 2020. https://doi.org/10.1590/0102-311X00104120

FERREIRA, MG; BARBOSA, EI. Antagonismo do isolamento: o distanciamento que protege e vulnerabiliza frente ao contexto de pandemia. Health Residencies Journal, v. 1, n. 3, p. 5-10, 2020. https://doi.org/10.51723/hrj.v1i3.36

FLORIANÓPOLIS, Prefeitura Municipal. Conselho Municipal de Saúde: em defesa do SUS, 2020a. Página inicial. Disponível em: <http://cms.pmf.sc.gov.br> Acesso em: 14 de dez. de 2020a.

FLORIANÓPOLIS, Prefeitura Municipal. Covidômetro: o controle em nossas mãos, 2020b. Página inicial. Disponível em: <https://covidometrofloripa.com.br> Acesso em: 15 de jul. de 2020b.

FLORIANÓPOLIS, Prefeitura Municipal. Secretaria Municipal de Saúde. Departamento de Assistência Farmacêutica. Sobre a mudança na validade das receitas de medicamentos de uso contínuo na rede municipal de saúde durante a pandemia do Coronavírus. Florianópolis. 16 mar. de 2020c. 
FRANCO, TB; MERHY, EE. O Reconhecimento de uma produção subjetiva do Cuidado. In: FRANCO, TB; MERHY, EE. Trabalho, produção do cuidado e subjetividade em saúde: textos reunidos. São Paulo: Hucitec, 2013. p. 151-171.

GARCIA, LP; et al.. O potencial de propagação da COVID-19 e a tomada de decisão governamental: uma análise retrospectiva em Florianópolis, Brasil. Rev. bras. epidemiol., v. 23, e200091, 2020. https://doi.org/10.1590/1980-549720200091

GAUDENZI, P; SCHRAMM, FR. A transição paradigmática da saúde como um dever do cidadão: um olhar da bioética em Saúde Pública. Interface (Botucatu), v. 14, n. 33, p. 243-255, 2010. https://doi.org/10.1590/S1414-32832010000200002

GUIZARDI, FL; CAVALCANTI, FOL. O conceito de cogestão em saúde: reflexões sobre a produção de democracia institucional. Physis, v. 20, n. 4, p. 1245-1265, 2010. https://doi.org/10.1590/S010373312010000400010

KIDD, MR. Five principles for pandemic preparedness: lessons from the australian covid-19 primary care response. British Journal Of General Practice, v. 70, n. 696, p. 316-317, 22 jun. 2020. http://dx.doi.org/10.3399/bjgp20x710765

KOSTER, ES; PHILBERT, D; BOUVY, ML. Impact of the COVID-19 epidemic on the provision of pharmaceutical care in community pharmacies. Research In Social And Administrative Pharmacy, v. 17, n. 1, p. 2002-2004, jan. 2021. http://dx.doi.org/10.1016/j.sapharm.2020.07.001

LEITE, SN; et al. Management of the health workforce in facing COVID-19: disinformation and absences in Brazil's Public Policies. Ciência \& Saúde Coletiva, v. 26, n. 5, p.1873-1884, 2021. https://doi.org/10.1590/1413-81232021265.01252021

LENTINE, EC; SONODA, TK; BIAZIN, DT. Estresse de profissionais de saúde das Unidades Básicas do Município de Londrina. Revista Terra \& Cultura, v. 19, n. 37, p. 103-123, 2020.

LIMA, AC; et al.. PROBLEMAS ÉTICOS NA ATENÇÃO BÁSICA: a visão de enfermeiros e médicos. Cogitare Enfermagem, v. 14, n. 2, p. 294-303, 2009. http://dx.doi.org/10.5380/ce.v14i2.15621

LIMA, LD; PEREIRA, AMM; MACHADO, CV. Crise, condicionantes e desafios de coordenação do Estado federativo brasileiro no contexto da COVID-19. Cad. Saúde Pública, v. 36, n. 7, e00185220, 2020. http://dx.doi.org/10.1590/0102-311X00185220

LIMA, NT; BUSS, PM; PAES-SOUSA, R. A pandemia de COVID-19: uma crise sanitária e humanitária. Cad. Saúde Pública, v. 36, n. 7, e00177020, 2020. http://dx.doi.org/10.1590/0102-311x00177020

MACAYA, P; ARANDA, F. Cuidado y autocuidado en el personal de salud: enfrentando la pandemia COVID-19. Revista Chilena de Anestesia, Las Condes, n. 1 v. 49, p. 356-362, abr. 2020.

MARIANI, F; et al.. Narrative Inquiry: experience and story in qualitative research. Translation: Narrative Inquiry Group and Teacher Education ILEEI/UFU. Uberlândia: EDUFU, 2011. 250 p. Educ. Públ., Cuiabá, v. 21, n. 47, p. 663-667, dez. 2012. 
MEDINA, MG; et al.. Atenção primária à saúde em tempos de COVID-19: o que fazer?. Cadernos de Saúde Pública, v. 36, n. 8, p. 1-5, 2020. http://dx.doi.org/10.1590/0102-311X00149720

MERHY, EE. SAÚDE: a cartografia do trabalho vivo. 4. ed. São Paulo: Hucitec, 2014.

MERHY, EE; FRANCO, TB. TRABALHO EM SAÚDE. In: PEREIRA, Isabel Brasil; LIMA, Júlio César França. Dicionário da educação profissional em saúde. Rio de Janeiro: Escola Politécnica de Saúde Joaquim Venancio, 2008. p. 278-283.

MOLINA, LR; HOFFMANN, JB; FINKLER, M. Ética e assistência farmacêutica na atenção básica: desafios cotidianos. Revista Bioética, v. 28, n. 2, p. 365-375, 2020. https://doi.org/10.1590/198380422020282398

MUÑOZ, JG. El valor de la auto-etnografía como fuente para la investigación social: del método a la narrativa. Revista Internacional de Trabajo Social y Bienestar, n. 3, p. 237-242, 2014.

OLIVEIRA, RJ; CUNHA, T. ESTRESSE DO PROFISSIONAL DE SAÚDE NO AMBIENTE DE TRABALHO: CAUSAS E CONSEQUÊNCIAS. Caderno saúde e Desenvolvimento, v. 3, n. 2, p. 79-93, dez. 2014.

ORNELL, F; et al.. The impact of the COVID-19 pandemic on the mental health of healthcare professionals. Cad. Saúde Pública, v. 36, n. 4, e00063520, 2020. https://doi.org/10.1590/0102$311 \times 00063520$

PAIVA, VLMO. A pesquisa narrativa: uma introdução. Rev. bras. linguist. apl., v. 8, n. 2, p. 261-266, 2008. https://doi.org/10.1590/S1984-63982008000200001

PASSOS, E; CARVALHO, YM. A formação para o SUS abrindo caminhos para a produção do comum. Saúde soc., v. 24, supl. 1, p. 92-101, 2015. https://doi.org/10.1590/S0104-12902015S01008

PEDUZZI, M; et al.. TRABALHO EM EQUIPE: UMA REVISITA AO CONCEITO E A SEUS DESDOBRAMENTOS NO TRABALHO INTERPROFISSIONAL. Trab. educ. saúde, v. 18, supl. 1, e0024678, 2020. https://doi.org/10.1590/1981-7746-sol00246

SANTA CATARINA. Decreto $\mathbf{n}^{\mathbf{0}}$ 515, de 17 de março de 2020. Declara situação de emergência em todo o território catarinense, nos termos do COBRADE $\mathrm{n}^{\circ}$ 1.5.1.1.0 - doenças infecciosas virais, para fins de prevenção e enfrentamento à COVID-19, e estabelece outras providências. Florianópolis, 2020.

SANTOS, CLM; et al.. Fatores de estresse na atividade de médicos em João Pessoa (PB, Brasil). Production, v. 21, n. 1, p. 181-189, 2011. https://doi.org/10.1590/S0103-65132011005000003

SARTI, TD; et al.. Qual o papel da Atenção Primária à Saúde diante da pandemia provocada pela COVID19?. Epidemiol. Serv. Saúde, v. 29, n. 2, e2020166, 2020. https://doi.org/10.5123/S167949742020000200024

SATURNINO, LTM; et al.. Farmacêutico: um profissional em busca de sua identidade. Revista Brasileira de Farmacia, v. 93, n. 1, p. 10-16, jan. 2012. 
SAVASSI, LCM; et al.. Ensaio acerca das curvas de sobrecarga da COVID-19 sobre a atenção primária. Journal Of Management \& Primary Health Care, v. 12, p. 1-13, 27 out. 2020. https://doi.org/10.14295/jmphc.v12.1006

SILVEIRA, JPM; ZONTA, R. Experiência de reorganização da APS para o enfrentamento da COVID-19 em Florianópolis. Aps em Revista, v. 2, n. 2, p. 91-96, 9 jun. 2020. https://doi.org/10.14295/aps.v2i2.122

WERNECK, GL; CARVALHO, MS. A pandemia de COVID-19 no Brasil: crônica de uma crise sanitária anunciada. Cad. Saúde Pública, v. 36, n. 5, e00068820, 2020. https://doi.org/10.1590/0102$311 \mathrm{X} 00068820$

ZOBOLI, ELCP. Bioética e atenção básica: para uma clínica ampliada, uma Bioética clínica amplificada. O Mundo da Saúde, v. 33, n. 2, p. 195-204, 2009. 